\title{
Research on the motion characteristics of composite Curve-face gear transmission
}

\author{
Chao LIN *, Yanan HU * and Yongquan YU * \\ * The State Key Laboratory of Mechanical Transmission, \\ Chongqing University, Chongqing, China \\ E-mail: linchao@cqu.edu.cn
}

Received: 21 September 2018; Revised: 11 March 2019; Accepted: 26 April 2019

\begin{abstract}
As a new type of gear transmission, composite curve-face gear transmission is used to transfer the power and composite motion of rotation and movement between the intersecting or interlaced axis. By using the theory of gear meshing, geometrical differential and space cam design, the motion principle and form of the composite curve-face gear transmission were discussed; the movement characteristics of the composite curve-face gear transmission were analyzed, including transmission ratio, rotation, movement and quick-return; the motion stability of the curve-face gear with different pitch curve forms was studied; and the forms of curve-face gear to realize stable and high-speed transmission were obtained. The correctness of the curve-face gear transmission is verified by experiment.
\end{abstract}

Keywords : Continuously variable transmissions, Gear design, Mechanism theory, High speed movement, QuickReturn

\section{Introduction}

With the research on technology of variable transmission ratio in parallel axis becoming mature gradually, people began to study the transmission of variable transmission ratio in intersecting transmission shaft. As a new non-standard gear transmission, intersecting axial variable transmission ratio gear mechanism mainly through the non-circular bevel gear mechanism to achieve this purpose (Gong, 2012). Composite motion of rotation and movement has been applied on many occasions, for example, textile machinery, agricultural machinery, light industrial machinery, processing center for knife exchange (ATC), cleaning mechanism and so on (Liu et al., 1997). The curve-face gear transmission is applied in high power transmission (Litvin and Fuentes, 2004). Erika Ottaviano, d. Mundo et al. have studied the application of the combination of non-circular gear and cam mechanism or linkage mechanism as function generator or path generation device (Mundo et al., 2009; Ottaviano et al.,2008). Jacek Bu, kiewicz, K. - h. Modler et al. have analyzed the general design method and optimization method of the geared 5-bar mechanism with non-circular gear (Buśkiewicz, 2010; Lin et al.,2013).

Curve-face gear composite transmission mechanism, which based on curve-face gear and combined with the characteristics of cam mechanism, gear mechanism and non-circular gear mechanism, is a new type of gear transmission (Liu, 2016). In the aspect of the transformation of the forms of motion, this new composite curve-face gear pair could convert the rotation of the driving wheel to the movement of the driven wheel like cam mechanism, and it also retained the function of transmitting the rotation motion between the two intersecting shafts as surface gear pair (Lin et al., 2016). As a new type of gear transmission (Litvin et al., 1992), composite curve-face gear mechanism. This kind of kinematic pair is simpler and more reliable than the traditional combined mechanism, which can replace some traditional combined mechanism, so it is of great importance to equipment lightweight and simplified mechanical structure. The research on the curve-face gear has been more detailed (Peng et al., 2016; Li and Zhu, 2010; Lu et al., 2000; Zhu, 1999; Huang et al., 2007; Ji , 2010; Sun et al., 2006), while the research on the curve-face gear composite transmission is less, focusing on the calculation of tooth surface, the law of motion and application. 


\section{Motion Principle}

\subsection{Principles Analysis of the Law of Motion}

Combining the curve-face gear with the cam mechanism, the law of the curve-face gear motion can be obtained. The cylinder gear is simplified as cylindrical roller, and the end surface gear is simplified as cylindrical cam, which together forms the cylindrical cam mechanism, where, the cylindrical cam as the driving part and the cylindrical roller as the driven part. While the driving part that the cylindrical cam rotate around a fixed axis, because of the change of the theoretical cam profile, the cylindrical roller move reciprocally, while the displacement is expressed s. While the cylindrical as driving part rotate around a fixed axis, because of the change of the pitch curve of the curve-face gear, the curve-face gear is used for reciprocating screw motion, while the displacement also is expressed s as shown in Fig.1.
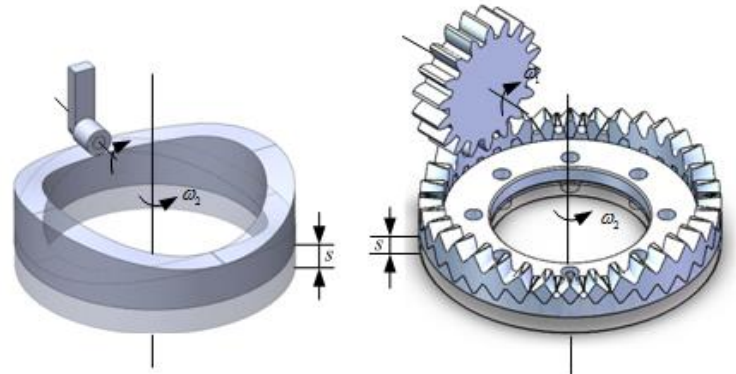

Fig.1. Principles figure of the law of motion

\subsection{Design of Pitch Curves of the Curve-face Gear Pair}

The solid model of the curve-face gear pair is shown in Fig.2(a). Pitch curves are the basis on the design of the gear transmission. The mathematical transmission model of the curve-face gear pair is built, as shown in the Fig.2(b). Where, $S(O-x, y, z), S_{1}\left(O_{1}-x_{1}, y_{1}, z_{1}\right)$ and $S_{2}\left(O_{2}-x_{2}, y_{2}, z_{2}\right)$ are space fixed coordinate systems; coordinate systems $S_{1}^{\prime}\left(O_{1}^{\prime}-x_{1}^{\prime}, y_{1}^{\prime}, z_{1}^{\prime}\right)$ and $S_{2}{ }^{\prime}\left(O_{2}^{\prime}-x_{2}{ }^{\prime}, y_{2}{ }^{\prime}, z_{2}{ }^{\prime}\right)$ fixed connect with the cylindrical gear and the curve-face gear respectively.

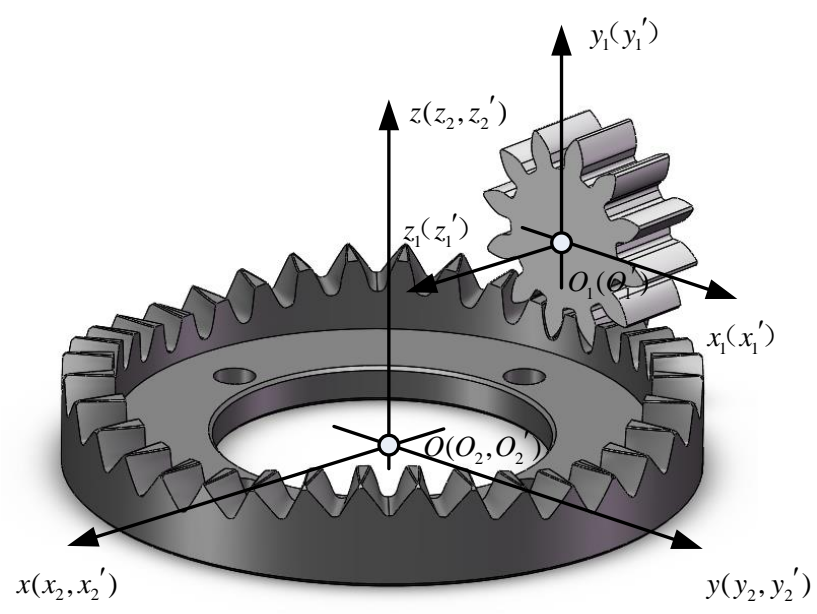

(a) The solid mode

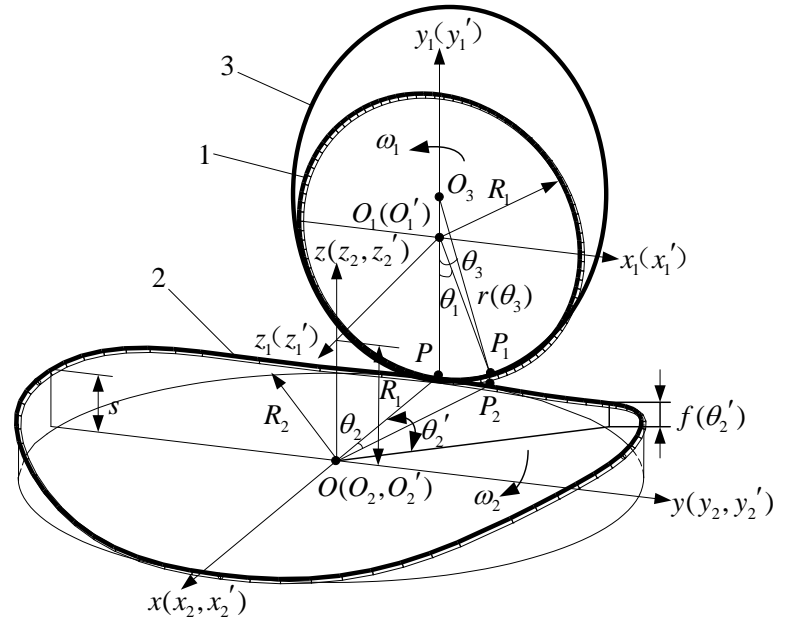

(b) The mathematical transmission model

Fig.2. The models of the curve-face gear pair

The curve-face gear pair can realize the expected motion law theoretically. In the fixed coordinate systems $S(O-x, y, z)$, according to the different motion laws of the curve-face gear pair, the pitch curve of the curve-face gear can be expressed as Table.1.

Table 1 The pitch curve of the curve-face gear.

\begin{tabular}{c|c|c}
\hline \hline Cylindrical gear & Curve-face gear & Imaginary non-circular gear \\
\hline$\left\{\begin{array}{l}x_{1}=-R_{2} \\
y_{1}=R_{1} \sin \theta_{1} \\
z_{1}=R_{1} \cos \theta_{1}\end{array}\right.$ & $\left\{\begin{array}{l}x_{2}=-R_{2} \cos \theta_{2} \\
y_{2}=-R_{2} \sin \theta_{2} \\
z_{2}=f\left(\theta_{2}\right)\end{array}\right.$ & $\left\{\begin{array}{l}x_{3}=-R_{2} \\
y_{3}=r\left(\theta_{3}\right) \sin \theta_{3} \\
z_{3}=r\left(\theta_{3}\right) \cos \theta_{3}\end{array}\right.$ \\
\hline
\end{tabular}


Where, the radius of cylindrical gear and curve-face gear are $R_{1}$ and $R_{2}$; the rotation angles of cylindrical gear, curveface gear and imaginary non-circular gear are $\theta_{1}, \theta_{2}$ and $\theta_{3} ; f\left(\theta_{2}\right)$ and $r\left(\theta_{3}\right)$, piecewise functions, represent the displacement of the curve-face gear and the polar radius of pitch curve of the imaginary non-circular gear.

The coordinate transformation from the moving coordinate system of the curve-face gear $S_{2}{ }^{\prime}$ to the moving coordinate system of the cylindrical gear $S_{1}{ }^{\prime}$ can be represented as

$$
M_{S_{1}^{\prime} S_{2}^{\prime}}=\left[\begin{array}{cccc}
\sin \theta_{1} \sin \theta_{2} & -\cos \theta_{2} \sin \theta_{1} & -\cos \theta_{1} & r(0) \cos \theta_{1} \\
-\cos \theta_{1} \sin \theta_{2} & \cos \theta_{1} \cos \theta_{2} & -\sin \theta_{1} & r(0) \sin \theta_{1} \\
-\cos \theta_{2} & -\sin \theta_{2} & 0 & -R_{2} \\
0 & 0 & 0 & 1
\end{array}\right]
$$

Because the $P_{1}$ and $P_{2}$ are coincident points, while the coordinate values of $P_{2}$ in the coordinate system $S_{1}{ }^{\prime}$ expressed as $\left[-\mathrm{R}_{2} \cos \theta_{2}-\mathrm{R}_{2} \sin \theta_{2} f\left(\theta_{2}\right)\right]$, the coordinate values of $P_{1}$ in the coordinate system $S_{2}{ }^{\prime}$ expressed as $\left[-\mathrm{R}_{2} \cos \theta_{2}-\mathrm{R}_{2} \sin \theta_{2} f\left(\theta_{2}\right)\right]$. Depending on the coordinate transformation, the coordinate values of $P_{1}$ in the coordinate system $S_{1}^{\prime}$ can be expressed as

$$
\left[\begin{array}{c}
x_{p_{1}^{\prime}} \\
y_{p_{1}^{\prime}} \\
z_{p_{1}^{\prime}} \\
1
\end{array}\right]=M_{S_{1}^{\prime} S_{2}^{\prime}}\left[\begin{array}{c}
-\mathrm{R}_{2} \cos \theta_{2} \\
-\mathrm{R}_{2} \sin \theta_{2} \\
f\left(\theta_{2}\right) \\
1
\end{array}\right]=\left[\begin{array}{c}
{\left[r(0)-f\left(\theta_{2}\right)\right] \cos \theta_{1}} \\
{\left[r(0)-f\left(\theta_{2}\right)\right] \sin \theta_{1}} \\
0 \\
1
\end{array}\right]
$$

According to Eq. (2), the conjugate curve of any cylinder pitch curve of the curve-face gear is the plant noncircular pitch curve. And the polar equation of the pitch curve of the noncircular gear in the coordinate system $S_{1}{ }^{\prime}$ is expressed as

$$
r\left(\theta_{3}\right)=f\left(\theta_{2}\right)
$$

Where, $\theta_{2}=g^{-1}\left(\theta_{1}\right)$. While the curve-face gear pair are in the transmission, the pitch curves are relatively pure rolling, so the arc lengths of the cylindrical gear 1 and the end surface gear 2 around the pitch curves are same. The relationship of $\theta_{1}$ and $\theta_{2}$ can be expressed as

$$
\theta_{1}=g\left(\theta_{2}\right)=\frac{1}{R_{1}} \int_{0}^{\theta_{2}} \sqrt{R_{2}^{2}+f^{\prime 2}(\theta)} d \theta
$$

Similarly, the arc lengths of the cylindrical gear 3 and the end surface gear 2 around the pitch curves are same. The relationship of $\theta_{3}$ and $\theta_{2}$ can be expressed as

$$
\theta_{2}=\frac{2 a \sqrt{1-k^{2}}}{n_{3} R_{2}} \arctan \left(\sqrt{\frac{1+k}{1-k}} \tan \frac{n_{3} \theta_{3}}{2}\right)
$$

Assuming that the modulus of compound transmission pair of end-curved gears is $m$, while the number of teeth of cylindrical gear is $z_{1}$, the pitch curve of cylindrical gear has a total length of $L_{1}$ in $2 \pi$ angle. And while the number of teeth of curve-face gear is $z_{2}$, the total length of pitch curve of curve-face gear in $2 \pi$ angle is $L_{2}$, which can be expressed as

$$
L_{2}=\int_{0}^{2 \pi} \sqrt{R_{2}^{2}+f^{\prime 2}\left(\theta_{2}\right)} d \theta_{2}
$$

In order to achieve curve-face gear composite transmission pair rotating continuously, it is required that the pitch curve of curve-face gear should be closed, and the length of the pitch curve of the curve-face gear is $n(n=1,2,3 \ldots)$ times that of the pitch curve of the cylindrical gear. Then, the pitch curve of the curve-face gear should satisfy the following 
conditions,

$$
n \pi m z_{1}=\int_{0}^{2 \pi} \sqrt{R_{2}^{2}+f^{\prime 2}\left(\theta_{2}\right)} d \theta_{2}
$$

Therefore, according to the above conditions, the radius of the curve-face gear $R_{2}$ can be inversely calculated. In other words, by controlling the radius of the curve-face gear $R_{2}$, the condition of continuous rotation of the curve-face gear can be satisfied.

\subsection{The Principle Analysis of the Laws of Motion of the Curve-face Gear}

Expanding the curve-face gear to rack, the motion of the three positions of the curve-face gear pair are shown as Fig. 3(a). While the cylindrical gear move to the position 1, the velocity direction of the meshing point $P_{11}$ in the pitch circle of the cylindrical gear parallel with the common tangent of the two pitch curves at the meshing point, and the velocity direction of the meshing point $P_{12}$ in the pitch curve of the rack move respectively along $\mathrm{y}$-axis and z-axis in the positive direction. While the cylindrical gear move to the position 2 and 3, the velocity direction of the meshing point $P_{21}$ and $P_{31}$ in the pitch circle of the cylindrical gear and the meshing point $P_{22}$ and $P_{32}$ in the pitch curve of the rack are also along yaxis in the positive direction. While the cylindrical gear rotate around the $z_{1}$-axis, the motion law of the curve-face gear pair moving to the general position is shown as Fig. 3(b). Where, the displacement velocity of the curve-face gear along the $\mathrm{z}$-axis is represented as $v_{S 2}$; the rotation velocity of the curve-face gear along the z-axis is represented as $v_{R 2}$; and the angle $\theta$ can be expressed as $\theta=\arctan \left(v_{S 2} / v_{R 2}\right)$.

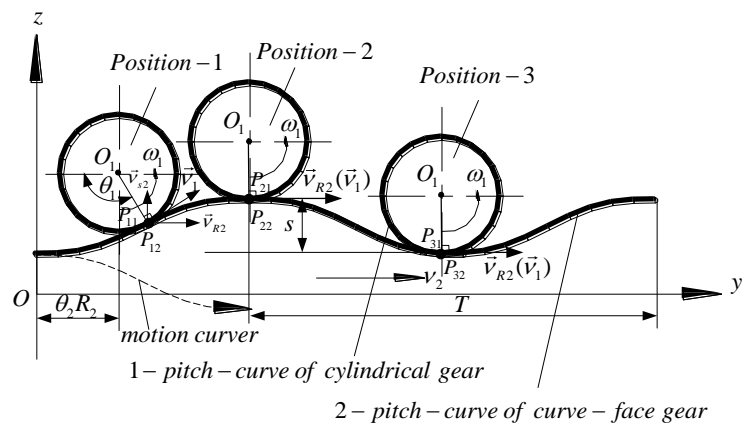

(a). The motion of the three positions of the rack and pinion mechanism

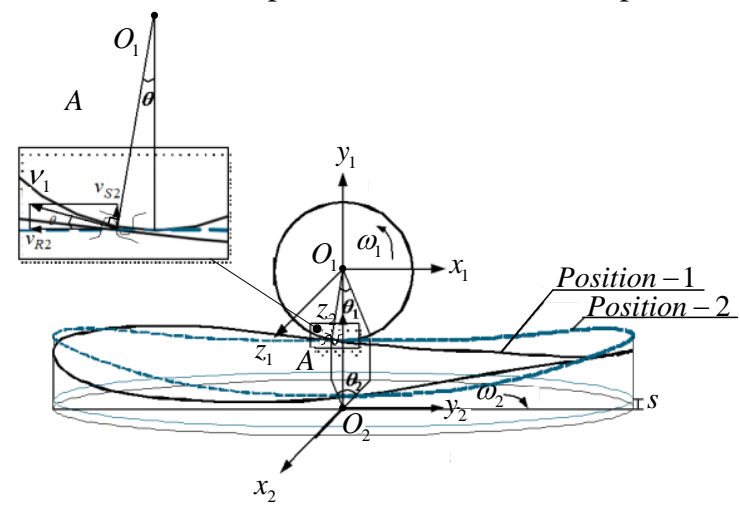

(b). The motion law of the curve-face gear pair moving to general position

Fig.3. The explanation of the motion of the curve-face gear pair

According to the motion characteristics of the regular motion of the cam mechanism, the curve of the motion curve suitable for high-speed motion is selected. In combination with the pitch curved form of the curve-face gear of the current study, $f\left(\theta_{2}\right)$ can be expressed as Table.2. 
Table.2 The displacement function of the curve-face gear $f\left(\theta_{2}\right)$

\begin{tabular}{l|l}
\hline \hline Forms of the pitch curve & Displacement function of the pitch curve \\
\hline $\begin{array}{l}\text { The motion curve derived } \\
\text { from non-circular curve (A) }\end{array}$ & $f\left(\theta_{2}\right)=r\left(\theta_{3}\right)=\frac{a\left(1-k^{2}\right)}{1-k \cos \left(n_{1} \theta_{3}\right)}$ \\
\hline $\begin{array}{l}\text { The sinusoidal acceleration } \\
\text { motion curve (B) }\end{array}$ & $f\left(\theta_{2}\right)= \begin{cases}s\left[\frac{\theta_{2}}{\Phi}-\frac{1}{2 \pi} \sin \left(\frac{2 \pi}{\Phi} \theta_{2}\right)\right] & 0 \leq \theta_{2} \leq \Phi \\
s\left[1-\frac{\theta_{2}}{\Phi^{\prime}}+\frac{1}{2 \pi} \sin \left(\frac{2 \pi}{\Phi^{\prime}} \theta_{2}\right)\right] & \Phi^{\prime} \leq \theta_{2} \leq T\end{cases}$ \\
\hline $\begin{array}{l}\text { The 3-4-5 index polynomial } \\
\text { motion curve (C) }\end{array}$ & $f\left(\theta_{2}\right)= \begin{cases}s\left[10\left(\frac{\theta_{2}}{\Phi^{3}}\right)^{3}-15\left(\frac{\theta_{2}}{\Phi^{2}}\right)^{4}+6\left(\frac{\theta_{2}}{\Phi^{\prime}}\right)^{5}\right] & 0 \leq \theta_{2} \leq \Phi \\
s\left[1-10\left(\frac{\theta_{2}}{\Phi^{\prime}}\right)^{3}+15\left(\frac{\theta_{2}}{\Phi^{\prime}}\right)^{4}-6\left(\frac{\theta_{2}}{\Phi^{\prime}}\right)^{5}\right] & \Phi^{\prime} \leq \theta_{2} \leq T\end{cases}$ \\
\hline
\end{tabular}

Where, $\Phi$ represents the rotation angle of the curve-face gear for rise in a cycle; $\Phi^{\prime}$ represents the rotation angle of the curve-face gear for return in a cycle T; $\Phi+\Phi^{\prime}=T=2 \pi / n ; n$ represents the degree of the curve-face gear; the motion curve derived from non-circular curve is named motion curve A; the sinusoidal acceleration motion curve is named motion curve $B$; the 3-4-5 index polynomial motion curve is named motion curve $\mathrm{C}$.

The pitch curve of the curve-face gear is a cylindrical curve, which the curvature radius of each point on it changes periodically. In order to ensure that the cylindrical gear are conjugate with the curve-face gear, the value range of the radius of the cylindrical gear $R_{2}$ should be determined. Considering that it is difficult to calculate the curvature radius of the segmented curve, through coordinate transformation, the conjugate curve of a non-cylindrical gear meshed with the curve-face gear could be reversed out and its minimum curvature radius of the pitch curve and the maximum radius of the cylindrical gear can be obtained.

About the motion curve $\mathrm{A}$, according to the curvature formula, while $n_{3}=1$, the minimum curvature radius of the imaginary non-circular gear pitch curve by MATLAB can be obtained, that $\rho_{3 \min }=48 \mathrm{~mm}$, and $R_{1} \leq \rho_{3 \min }=48 \mathrm{~mm}$. However, the curvature radius of the motion curve $\mathrm{B}$ and $\mathrm{C}$ can be obtained directly by the curvature formula to acquire the minimum curvature radius. While $R_{2}=100 \mathrm{~mm}, n=2$, the value rang of the cylindrical gear is $R_{1} \leq 100 \mathrm{~mm}$ 。

\subsection{The Law of the Transmission Ratio of the Curve-face Gear Pair}

Combining with Eq. (4), computational formula of transmission ratio can be expressed as

$$
i_{12}=\frac{\omega_{1}}{\omega_{2}}=\frac{d \theta_{1}}{d \theta_{2}}=\frac{1}{R_{1}} \sqrt{R_{2}^{2}+f^{\prime 2}\left(\theta_{2}\right)}
$$

According to Eq. (8), angular velocity $\omega_{2}$ and rotational speed $n_{2}$ can be obtain.

$$
n_{2}=\frac{R_{1}}{\sqrt{R_{2}^{2}+f^{\prime 2}\left(\theta_{2}\right)}} n_{1}, \omega_{2}=\frac{2 \pi n_{2}}{60}
$$

Angular acceleration $\alpha_{2}$ can be obtained by Eq. (9).

$$
\alpha_{2}=\frac{d \omega_{2}}{d t}=-\left(R_{1} \omega_{1}\right)^{2} \frac{f^{\prime}\left(\theta_{2}\right) f^{\prime \prime}\left(\theta_{2}\right)}{\left[R_{2}^{2}+f^{\prime 2}\left(\theta_{2}\right)\right]^{2}}
$$

When the input of the end surface gear pair that the rotational speed of the cylindrical gear is constant, the value of the rotational speed and the angular velocity of the curve-face gear only have to do with the transmission ratio by Eq. (7). According to the study in paper (Cai, 2017), the limitation of design parameters and operation range are given. While 
$k=0.1, n_{3}=1, n=2, R_{1}=48 \mathrm{~mm}, R_{2}=100 \mathrm{~mm}, a=50 \mathrm{~mm}, s=5.5 \mathrm{~mm}, n_{1}=200 \mathrm{r} / \mathrm{min}$, the rotational speed of the curveface gear and transmission ratio can be expressed as Fig. 4.

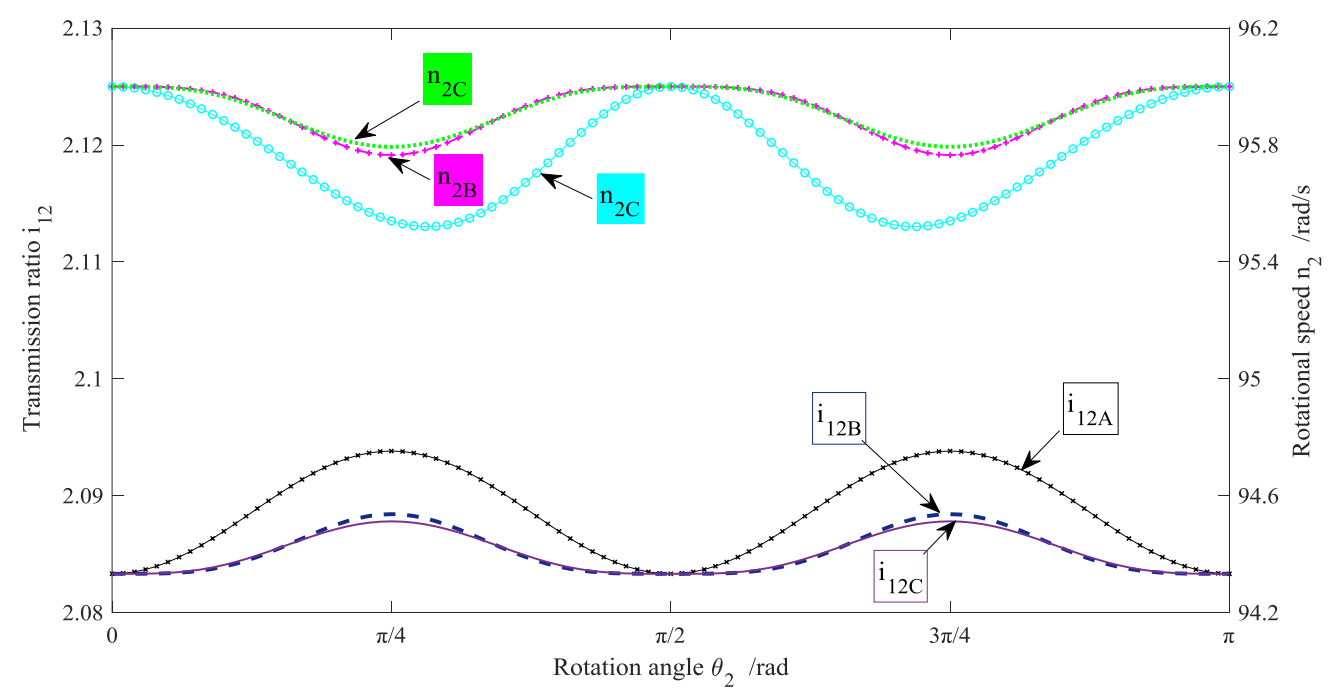

Fig.4. Transmission ratio and rotational speed $n_{2}$ of different motion curve in a cycle

According to Fig.4, the transmission ratio is the largest with the motion curve A as the pitch curve; the motion curve $\mathrm{A}$ and $\mathrm{B}$ as the pitch curve, the transmission ratios are almost as small. Relatively speaking, the motion curve A can realize the large transmission ratio transmission. Because $s$ is far less than $R_{2}$, the transmission ratio have a little change, which the value range is from 2.082 to 2.096 . In a nutshell, the transmission ratio of the end surface gear pair is transient by Fig. 4.

\section{Analysis of Curve-face Gear about the Composite Motion}

The absolute motion of the curve-face gear is the space composite motion of the axial movement and the fixed-axis rotation. The kinetic characteristic of this motion is complicated, so that the method of point motion synthesis can be used to solve this problem. And the absolute motion of the curve-face gear is the space composite motion; the relative motion is that the curve-face gear moves along the $\mathrm{z}$-axis in the moving coordinate system $S_{2}{ }^{\prime}$; the transport motion is that the moving coordinate system $S_{2}{ }^{\prime}$ turn around the z-axis relative to the fixed coordinate system $S_{2}$. The equation of the law of curve-face gear about the composite motion is shown as Table. 3. 
Table.3 The equation of the law of curve-face gear about the composite motion

\begin{tabular}{|c|c|c|}
\hline Motion & Parameter & Not recommended \\
\hline \multirow{2}{*}{ Relative motion } & Velocity & $\vec{v}_{r}=\left(0,0,-f^{\prime}\left(\theta_{2}\right)\right) \omega_{2}$ \\
\hline & Acceleration & $\vec{a}_{r}=\left(0,0,-f^{\prime \prime}\left(\theta_{2}\right) \omega_{2}-f^{\prime}\left(\theta_{2}\right) \alpha_{2}\right)$ \\
\hline \multirow{2}{*}{ Transport motion } & Velocity & $\vec{v}_{e}=\left(-R_{2} \sin \theta_{2},-R_{2} \cos \theta_{2}, 0\right) \omega_{2}$ \\
\hline & Acceleration & $\vec{a}_{e}=\left(-R_{2} \cos \theta_{2}, R_{2} \sin \theta_{2}, 0\right) \alpha_{2}$ \\
\hline \multirow[b]{3}{*}{ Absolute motion } & Velocity & $\begin{array}{l}\vec{v}_{a}=\vec{v}_{r}+\vec{v}_{e}=\left(-R_{2} \sin \theta_{2},-R_{2} \cos \theta_{2},-f^{\prime}\left(\theta_{2}\right)\right) \omega_{2} \\
\left|\vec{v}_{a}\right|=\sqrt{R_{2}^{2}+\left[f^{\prime}\left(\theta_{2}\right)\right]^{2}} \omega_{2}\end{array}$ \\
\hline & Coriolis' acceleration & $\vec{a}_{c}=\left(\sin \theta_{2}, \cos \theta_{2}, 0\right) f^{\prime}\left(\theta_{2}\right) \omega_{2}^{2}$ \\
\hline & Acceleration & $\begin{aligned} \vec{a}_{a}= & \vec{a}_{r}+\vec{a}_{e}+\vec{a}_{c} \\
= & \left(-R_{2} \cos \theta_{2} \alpha_{2}+\sin \theta_{2} \omega_{2}{ }^{2}, R_{2} \sin \theta_{2} \alpha_{2}+\cos \theta_{2} \omega_{2}{ }^{2},\right. \\
& \left.-f^{\prime \prime}\left(\theta_{2}\right) \omega_{2}-f^{\prime}\left(\theta_{2}\right) \alpha_{2}\right) \\
\left|\vec{a}_{a}\right|= & \sqrt{R_{2}{ }^{2} \alpha_{2}{ }^{2}+\omega_{2}{ }^{4}+\left(f^{\prime \prime}\left(\theta_{2}\right) \omega_{2}+f^{\prime}\left(\theta_{2}\right) \alpha_{2}\right)^{2}}\end{aligned}$ \\
\hline
\end{tabular}

By applying the method of point motion synthesis to solve the absolute motion of the curve-face gear, the absolute motion of the curve-gear is resolved. The absolute velocity $\vec{v}_{a}$ is resolved into rotation velocity $\vec{v}_{R}$ around the z-axis and movement velocity $\vec{v}_{S}$ along the z-axis; similarly, the absolute acceleration $\vec{a}_{a}$ is resolved into rotation acceleration $\vec{a}_{R}$ around the z-axis and movement acceleration $\vec{a}_{S}$ along the z-axis. Equations are shown as Eq. (11) and Eq. (12).

$$
\begin{aligned}
& v_{R}=\left|\vec{v}_{R}\right|=R_{2} \omega_{2}=\frac{R_{1} R_{2}}{\sqrt{R_{2}^{2}+f^{\prime 2}\left(\theta_{2}\right)}} \omega_{1} \quad v_{S}=\left|\vec{v}_{S}\right|=f^{\prime}\left(\theta_{2}\right) \omega_{2}=\frac{R_{1} f^{\prime}\left(\theta_{2}\right)}{\sqrt{R_{2}^{2}+f^{\prime 2}\left(\theta_{2}\right)}} \omega_{1} \\
& a_{R}=\left|\vec{a}_{R}\right|=\left(R_{2} \alpha_{2}\right)^{2}+\left(\omega_{2}^{2}\right)^{2}=\frac{R_{2}^{2}\left(R_{1} \omega_{1}\right)^{4} f^{\prime 2}\left(\theta_{2}\right) f^{\prime \prime 2}\left(\theta_{2}\right)}{\left[R_{2}^{2}+f^{\prime 2}\left(\theta_{2}\right)\right]^{4}}+\frac{\left(R_{1} \omega_{1}\right)^{4}}{\left[R_{2}^{2}+f^{\prime 2}\left(\theta_{2}\right)\right]^{2}} \\
& a_{S}=\left|\vec{a}_{S}\right|=f^{\prime \prime}\left(\theta_{2}\right) \omega_{2}+f^{\prime}\left(\theta_{2}\right) \alpha_{2}=\frac{R_{1} \omega_{1} f^{\prime \prime}\left(\theta_{2}\right)}{\sqrt{R_{2}^{2}+f^{\prime 2}\left(\theta_{2}\right)}}-\frac{\left(R_{1} \omega_{1}\right)^{2} f^{\prime 2}\left(\theta_{2}\right) f^{\prime \prime}\left(\theta_{2}\right)}{\left[R_{2}^{2}+f^{\prime 2}\left(\theta_{2}\right)\right]^{2}}
\end{aligned}
$$

To research on the impact of the curve-face gear pair at run time, movement jerk is made as a measure of standard. The movement jerk is obtained by differentiating the acceleration about time $t$ and is represented as

$$
j_{s}=f^{\prime \prime \prime}\left(\theta_{2}\right) \omega_{2}^{2}+f^{\prime \prime}\left(\theta_{2}\right) \alpha_{2}\left(1+\omega_{2}\right)+f^{\prime}\left(\theta_{2}\right) j_{\alpha}
$$

Where, $j_{\alpha}$ can be obtained by differentiating angular acceleration about time $t$. While $k=0.1, n_{3}=1, n=2, R_{1}=48 m m$, $R_{2}=100 \mathrm{~mm}, a=50 \mathrm{~mm}, \mathrm{~s}=5.5 \mathrm{~mm}, n_{1}=200 \mathrm{r} / \mathrm{min}$, the kinetic characteristics of the curve-face gear about three different motion curve can be obtained as shown in Fig. 5(a)-(d), including angular velocity $\omega_{2}$, angular acceleration $\alpha_{2}$, rotational velocity $v_{R}$, rotational acceleration $a_{R}$, movement speed $v_{S}$, translational acceleration $a_{S}$ and movement jerk $j_{S}$. 


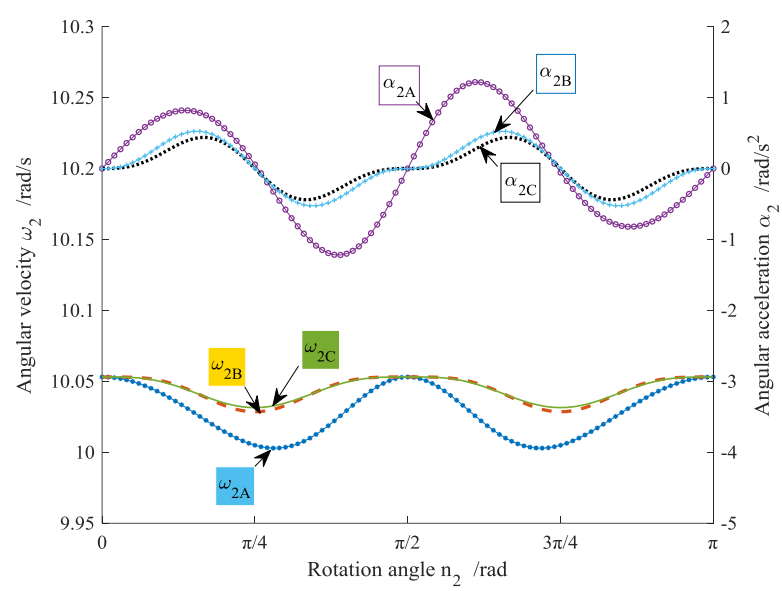

(a) Angular velocity, angular acceleration

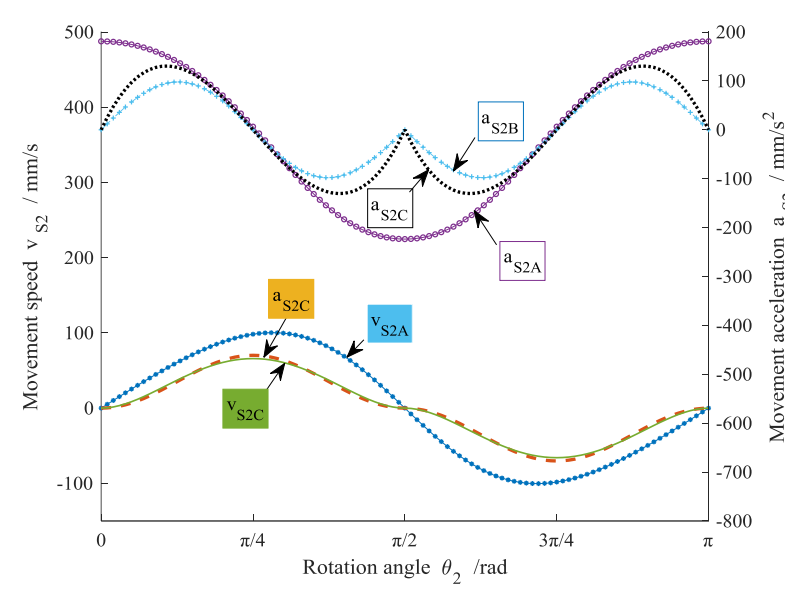

(c) Movement speed, translational acceleration

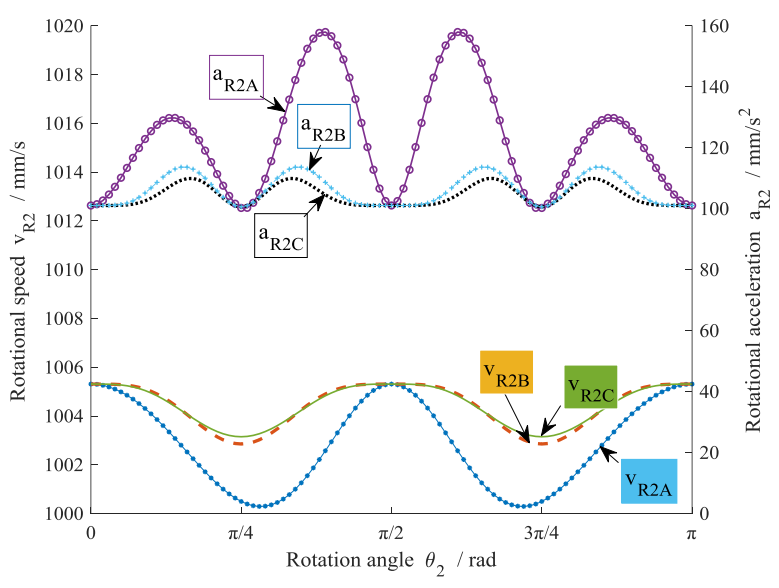

(b) Rotational velocity, rotational acceleration

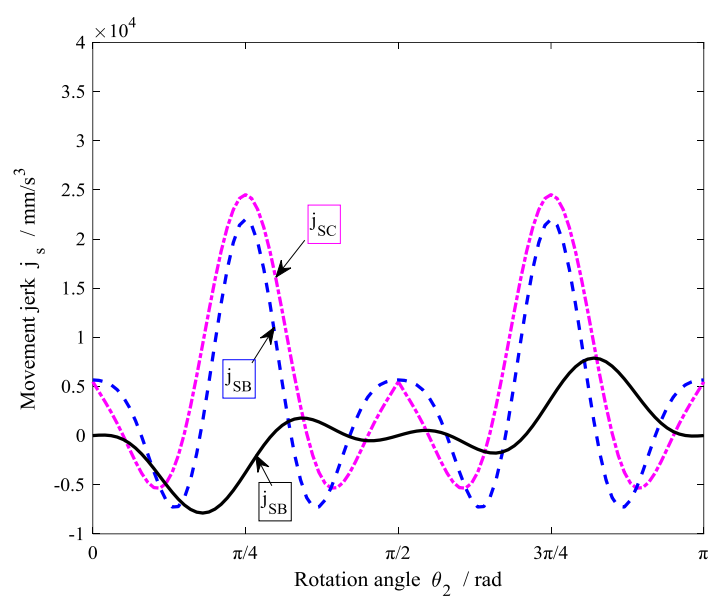

(d) Movement jerk

Fig.5. The kinetic characteristic of different motion curve in a cycle

According to Fig. 5(a)-(d), the kinetic characteristics of different motion curve can be obtained.

1) The rotational characteristics of the curve-face gear

Except for the radius of two gear and input angular velocity, the laws of the angular velocity and the angular acceleration of the curve-face gear is a periodic function related to transmission ratio in a cycle, so the range of angular velocity and angular acceleration vary in different pitch curve as shown in Fig. 5(a). According to Eq. (11), the laws of the rotational velocity of the curve-face gear is same as angular velocity, and it also does not change very much that ranges from 1000.3 to 1005.3 as shown in Fig. 5(b). The rotational acceleration of the curve-face gear is related to its angular velocity and its angular acceleration, and its angular velocity has more influence on rotational acceleration by Eq. (12). In general, the curve of rotational acceleration of the curve-face gear is an axisymmetric function with changing in a large range from 100.26 to 157.97. Increasing the input speed, the maximum rotational acceleration will grow seriously, and the form of the pitch curve also has some influence on its value as shown in Fig. 5(b).

2) The movement characteristics of the curve-face gear

About the movement of the curve-face gear, it is a reciprocating motion, which curve is central symmetry. During the movement, the stroke s and angular velocity $\omega_{2}$ are the decisive factors by Eq. (11).Of course, the maximum and the minimum movement velocity, varying with the pitch curve, are opposite numbers of each other. The movement acceleration of the curve-face gear is more complex. The value of its movement acceleration is related to its pitch curve, the angular velocity and angular acceleration by Eq. (12), whose range is from -223.52 to 180.96. And the different pitch curves affect the wave direction of its movement acceleration curve. While the motion curve of empty return and impulse stroke are symmetrical, the resulting curve of movement acceleration is also axisymmetric as shown in Fig. 5(c).

3) The comparison of the kinetic characteristics of the curve-face gear pair in different pitch curve

From Fig. 4 and Fig.5, it is observed that the different pitch curve have a big effect on angular acceleration $\alpha_{2}$, rotational acceleration $a_{R}$, movement velocity $v_{S}$ and movement acceleration $a_{S}$ of the curve-face gear, and have a little effect on others. The characteristics of different motional laws can be obtained. 
Motional law of curve A The moving velocity curve is continuous, but in the initial position of the motion, the acceleration curve has a limited mutation, which produces a soft shock. When the motion is continuous, the acceleration curve is continuous with a limited mutation in the initial position, so the impact only exists at the beginning of the movement. The motional law of curve A is applied to occasion of low speed and medium load.

Motional law of curve B Both the curves of movement velocity and the movement acceleration are continuous without mutation. Therefore, there is neither rigid impact nor soft impact during the motion. The motional law of curve B is suitable for high speed and medium load situations.

Motional law of curve C Both the curves of movement velocity and the movement acceleration are continuous without mutation. Therefore, there is neither rigid impact nor soft impact during the motion. The motional law of curve $\mathrm{C}$ is suitable for high speed and light load situations. The characteristics of three motional laws and the recommended application are listed in the Table. 4.

Table.4. The characteristics of three motional laws and the recommended application

\begin{tabular}{c|c|c|c|c|c}
\hline \hline Motional law & Impact & $v_{S \max }$ & $a_{S \max }$ & $j_{S \max }$ & Application \\
\hline Movement curve A & Soft & 99.51 & 201.06 & 7883.4 & $\begin{array}{c}\text { Low speed } \\
\text { Medium load }\end{array}$ \\
\hline Movement curve B & Nun & 70.21 & 97.95 & 22007 & $\begin{array}{c}\text { High speed } \\
\text { Medium load }\end{array}$ \\
\hline Movement curve C & Nun & 65.85 & 130.32 & 24518 & $\begin{array}{c}\text { High speed } \\
\text { Light load }\end{array}$ \\
\hline
\end{tabular}

\section{The Quick-Return Characteristics of the Curve-face Gear Pair}

The quick-return characteristics is applied to the curve-face gear pair, which take the slower stroke as the working stroke to ensure the smooth movement and improve the quality of work, and the quicker stroke as the return stroke to improve the efficiency of the work. As shown in Fig.6, the curve-face gear pair is transformed into a space five-bar mechanism by means of low pair replacing high pair. Where, $\mathrm{P}$ is the instantaneous meshing point; A and B are the instantaneous centers of rotation of the cylinder gear 1 and the curve-face gear 2 respectively. When the driving part 1 rotates around the fixed axis, the motion of the driven composite motional part is made to movement along the $\mathrm{z}$-axis and rotation around the $\mathrm{z}$-axis.

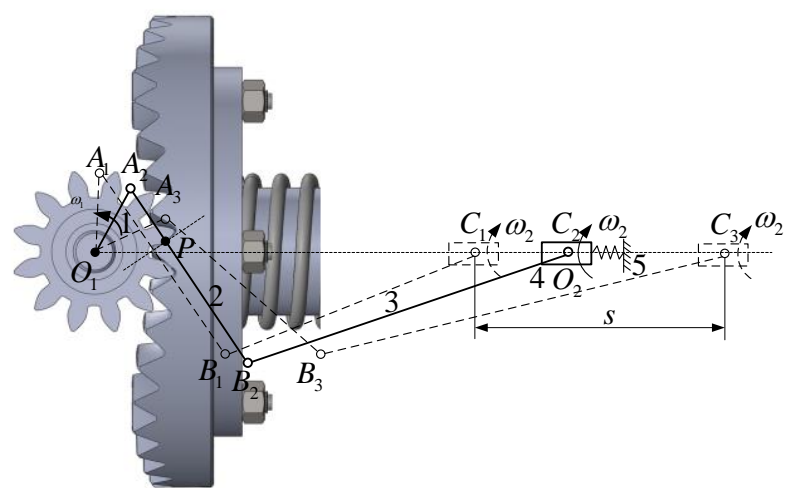

Fig.6. The space five-bar mechanism transformed from the curve-face gear pair by means of low pair replacing high pair The movement characteristics of the curve-face gear 2 is a reciprocating movement, and when the velocity of working stroke is not same as the return stroke, it is necessary to explore its quick-return characteristics. While the driving part is a uniform motion, the average speed of the return stroke of the driven part for reciprocating motion is greater than the working stroke. The stoke ratio coefficient $r$ can be expressed as

$$
r=\frac{v_{2}}{v_{1}}=\frac{s / t_{2}}{s / t_{1}}=\frac{t_{1}}{t_{2}}, \quad\left\{\begin{array}{l}
r>1 \text { with quick-return characteristics } \\
r=1 \text { without quick-return characteristics }
\end{array}\right.
$$


Where, the average speed of the working stroke represents as $v_{1}$; the average speed of the return stroke represents as $v_{2}$; $t_{1}$ and $t_{2}$ express the movement time of working stroke and return stroke respectively. With the basic parameters being at the same value, the angle of rise travel can be set as $\Phi=\left[\frac{\pi}{2}, \frac{3}{5} \pi, \frac{2}{3} \pi\right]$.The movement velocity diagram of motion curve $\mathrm{B}$ and $\mathrm{C}$ in different angle of rise travel can be obtained as shown in Fig. 7(a)-(b).

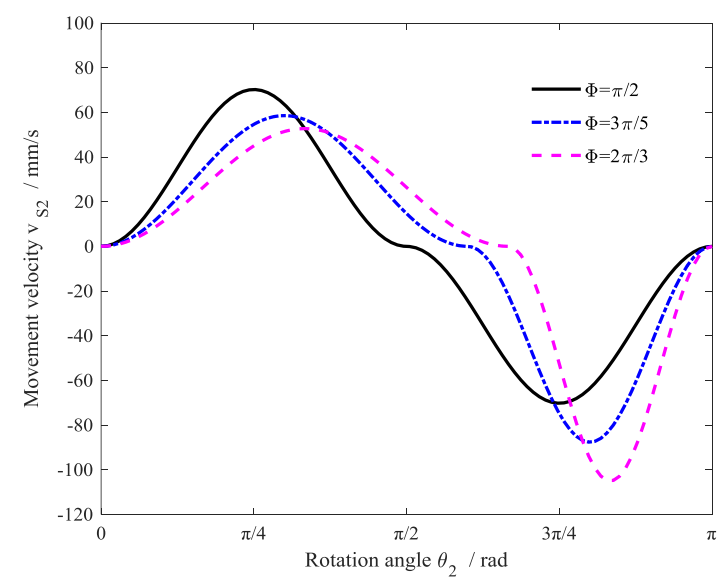

(a) Motion curve B

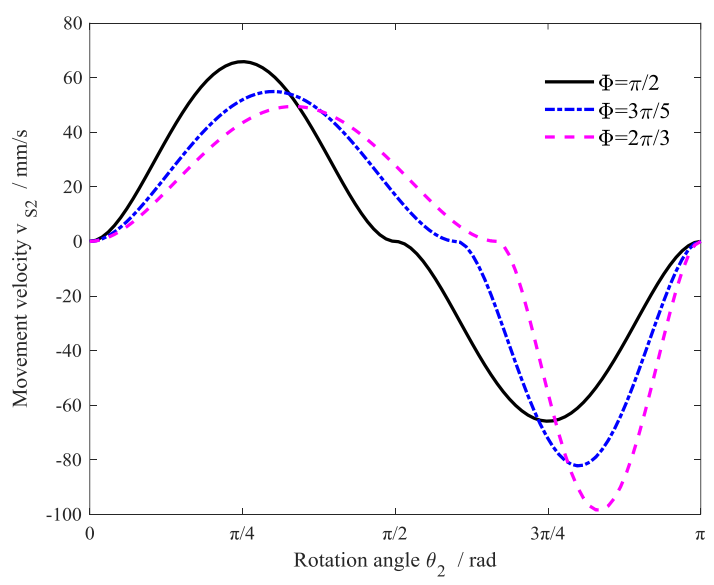

(b) Motion curve $\mathrm{C}$

Fig.7. The movement velocity diagram in different angle of rise travel

From Fig. 7, it can be visible seen that the movement velocity of certain motional law may differ depending on the angle of rise travel. According to Eq. (13), with the same values of basic parameters, expect for the angle of rise travel, the quick-return characteristics of the curve-face gear pair can be obtained as shown in Table. 5 .

Table.5. Analysis table of the quick-return characteristics.

\begin{tabular}{|c|c|c|c|c|c|c|}
\hline Motional law & \multicolumn{3}{|c|}{ Motion curve B } & \multicolumn{3}{|c|}{ Motion curve $\mathrm{C}$} \\
\hline Angle of rise travel $\Phi$ & $\frac{\pi}{2}$ & $\frac{3 \pi}{5}$ & $\frac{2 \pi}{3}$ & $\frac{\pi}{2}$ & $\frac{3 \pi}{5}$ & $\frac{2 \pi}{3}$ \\
\hline Average speed of the working stroke $v_{1}$ & 51.1007 & 42.6091 & 38.3580 & 51.1054 & 42.6118 & 38.3600 \\
\hline Average speed of the return stroke $v_{2}$ & 51.1007 & 63.8064 & 76.4666 & 51.1054 & 63.8156 & 76.4822 \\
\hline Stoke ratio coefficient $r$ & 1 & 1.4975 & 1.9935 & 1 & 1.4976 & 1.9938 \\
\hline Value of $\Phi / \Phi^{\prime}$ & 1 & 1.5 & 2 & 1 & 1.5 & 2 \\
\hline
\end{tabular}

Comparing stoke ratio coefficient $\mathrm{r}$ and the value of $\Phi / \Phi^{\prime}$ from Tab.5, the stoke ratio coefficient $\mathrm{r}$ of second order curve-face gear is same as the value of $\Phi / \Phi^{\prime}$ in a cycle that $\theta_{2} \in[0, \pi]$. Therefore the required stoke ratio coefficient $\mathrm{r}$ can be obtained by changing the values of the angles of rise travel and return travel.

\section{Experiment Confirm}

To verify the correctness of the theory, the curve-face gear is machined by generating method. 1) The motion trajectory of the cylindrical spur gear and the curve-face gear meshing is calculated, and by the simulating manufacturing and characteristic analysis system of the orthogonal non-circular surface gear, the spur cylindrical gear is used as a tool to cut out the profile of the conjugate curve-face gear; 2) A series of subsequent optimizations of the curve-face gear are 
introduced into Solidworks, including teeth surface finishing, blade root fillet and so on; 3) The curve-face gear pair entity can be obtained by the five axis CNC machining and corresponding heat treatment ; 4) Based on the layout plan of experiment station, the experimental table of the gears is set up shown as Fig.8. Changing the motor speed and the torque of the loader by control desk, the output of the sensor can be observed, and the transmission characteristics of the curve-face gear pairs was obtained by using measuring software to measure and process the data. The specifications of measured curve-face gear pair are follow: the module of this gear pair $m$ is $4 m m$; the number of teeth on cylindrical gear $z_{1}$ is 18 ; the number of teeth on curve-face gear $z_{2}$ is 36 ; the pressure angle of cylindrical gear $\alpha_{1}$ is $20^{\circ}$.

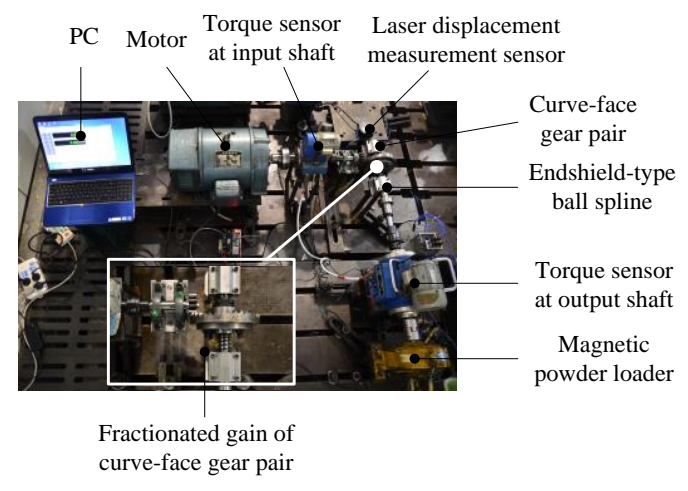

Fig.8. Experimental table of the gears

This experiment is mainly to verify the correctness of the characteristics of axial displacement and transmission ratio. The axial movement can be obtained by the laser displacement measurement sensor directly. Through using input and output shaft torque sensor to obtain the corresponding revolving speed and torque data of input and output shaft, according to the transmission ratio formula, transmission ratio curve can be obtained.

The comparison of axial displacement is shown in the Fig. 9(a). The theoretical value of axial displacement is roughly the same as the measured value in the curve waveform, but the maximum value of the measured displacement is slightly larger than the theoretical value. The value of the measured axial displacement is $-5.893 \mathrm{~mm}$ and the theoretical value is $-5.5 \mathrm{~mm}$, which relative deviation is $7.1 \%$. From Fig. 9(a), at the position of the first trough, the deviation is smaller, while there is a larger deviation at the second trough, which caused by the installation error of the gear pair, measuring error and the delay of mechanism due to the spring. Among the causes of this situation, the most important one is the delay of the mechanism caused by the spring, which helps the curve-face gear to return to its original position. Replacing the spring with the bilateral teeth of the curve-face gear will effectively reduce the axial displacement error. The above analysis shows that the experimental results can verify the validity of theoretical axial displacement.

The comparison of transmission ratio is shown in the Fig. 9(b). The theoretical value of the transmission ratio is basically consistent with the measured value about the change trend. The average measured transmission ratio is 2.087 , and the theoretical transmission ratio is 2.088 , which relative deviation is very small. The experimental results also can verify the validity of theoretical transmission ratio.

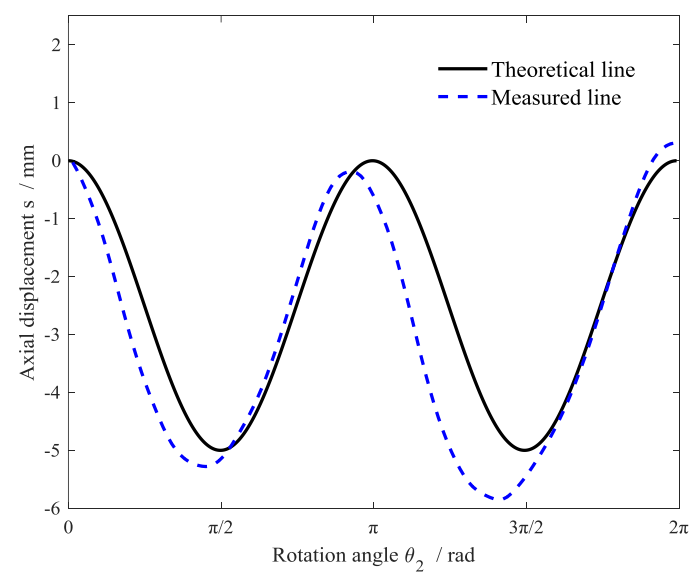

(a) Axial displacement

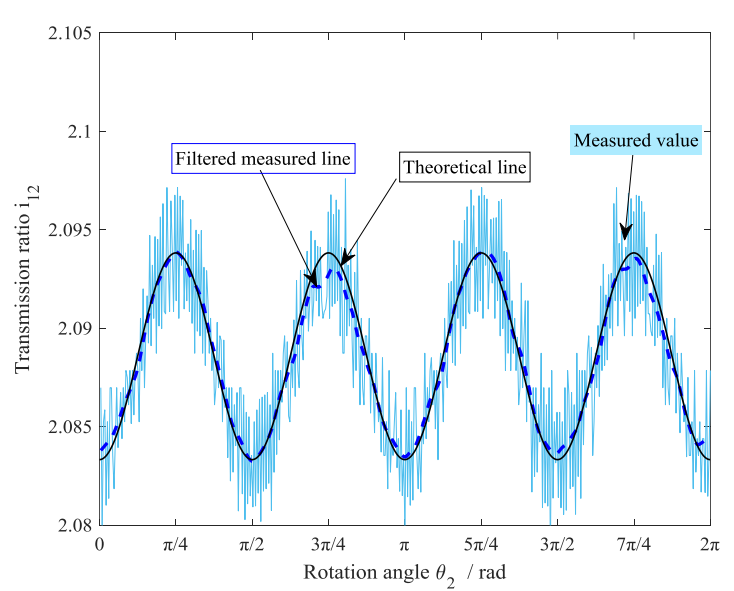

(b) Transmission ratio

Fig.9. The comparison of theoretical value to measured value 


\section{Conclusions}

In this paper, the main research contents are summarized as follows:

1) In order to realize the requirements of high speed movement of curve-face gear, combining with the relevant theory of spatial cam, in this paper, the three main forms of pitch curve are put forward and its movement characteristics have been carried on the comparison and analysis. It lay a foundation of the study on achieving different movement forms of curve-face gear pair.

2) Through analyzing the restrictions of high speed movement of the curve-face gear pair, it turned out that: while the motion curve B is as pitch curve, the impact of the curve-face gear pair is smaller, and high speed transmission can be realized.

3) The quick-return characteristics of the curve-face gear pair can be obtained by reasonable changing the angle of working travel and the return travel, which can improve the working stability and the working efficiency of the curveface gear pair transmission.

4) The correctness of the motion characteristics of the curve-face gear is verified by the experiments of the axial movement and transmission ratio of the curve-face gear.

\section{Acknowledgment}

The author would like to thank the National Natural Science Foundation of China (No. 51675060) and Project NO. 106112017CDJPT280002 Supported by the Fundamental Research Funds for the Central Universities for financially supporting this work. This work was also supported by the State Key Laboratory of Mechanical Transmission of Chongqing University (No.SKLMT-ZZKT-2015Z16).

\section{References}

Buśkiewicz, J., Use of shape invariants in optimal synthesis of geared five-bar linkage, Mechanism \& Machine Theory, Vol.45, No.2 (2010), pp. 273-290.

Cai, Z., Study on the Time-Varying Meshing Design and Characteristics Analysis of Curve-face Gear Drive, Chongqing University, (2017) (in Chinese).

Gong, H., The transmission design and characteristic analysis of orthogonal non-circular surface gears, Chongqing University, (2012) (in Chinese).

Huang, L. J., and Zhu, R. P., The Generation of Face-Gear Drive with Helical Pinion, Mechanical Engineer, Vol.34, No.2 (2007), pp. 58-60.

Ji, C., Design and Gear Shaping Experiment on Orthogonal Face Gear, Journal of Mechanical Transmission, Vol.34, No.2 (2010), pp. 58-60.

Li, Z., and Zhu, R., Load tooth contact analysis on face gear driver, Journal of Nanjing University of Aeronautics \& Astronautics, Vol.42, No.2 (2010), pp. 219-223.

Lin, C., Gong, H., Nie, N., Zeng, Q. L., and Zhang, L., Geometry design, three-dimensional modeling and kinematic analysis of orthogonal fluctuating gear ratio face gear drive, Proceedings of Institution of Mechanical Engineers Part C Journal of Mechanical Engineering Science, Vol.227, No.4 (2013), pp. 779-793.

Lin, C., and Liu, Y., Characteristic analysis and application of composite motion curve-face gear pair, Journal of the Brazilian Society of Mechanical Sciences \& Engineering, Vol.38, No.6 (2016), pp. 1797-1804.

Litvin, F. L., Zhang, Y., and Wang, J. C., et al, Design and Geometry of Face-Gear Drives, Journal of Mechanical Design, Vol.114, No.4 (1992), pp. 642-647.

Litvin, F. L., and Fuentes, A., Gear Geometry and Applied Theory (2004), Cambridge University Press.

Liu, C. Q., Makino, H., and Cao, X. J., Cam mechanism design (1997), China Machine Press (in Chinese).

Liu, Y., The design and analysis of the composite motion of the curve-face gear, Chongqing University (2016) (in Chinese).

Lu, W. L., Zhu, R. P., and Zeng, Y., Study on Tooth Surface Curvature for Orthogonal Face-Gear Drives, Journal of Nanjing University of Aeronautics \& Astronautics, Vol.32, No.4 (2000), pp. 400-404.

Mundo, D., Gatti, G., and Dooner, D. B., Optimized five-bar linkages with non-circular gears for exact path generation, 
Mechanism \& Machine Theory, Vol.44, No.4 (2009), pp. 751-760.

Ottaviano, E., Mundo, D., and Danieli, G. A., et al, Numerical and experimental analysis of non-circular gears and camfollower systems as function generators, Mechanism \& Machine Theory, Vol.43, No.8 (2008), pp. 996-1008.

Peng, X. L., Zhang, L., and Fang, Z., Manufacturing process for a face gear drive with local bearing contact and controllable meshing performance based on ease-off surface modification, Journal of Mechanical Design, 138(4). Vol.138, No.4 (2016) (in Chinese).

Sun, H., Chen, Z. M., and Ge, W. J., Theory of machines and mechanisms (2006), Higher Education Press (in Chinese).

Zhu, R., Study of the Design of Tooth Width of Right Shaft angle Face Gear Drive, Mechanicalence \& Technology, Vol.40, No.10 (1999), pp. 10-13 (in Chinese). 